\title{
Possible impact of forest product certification on the worldwide forest environment
}

\author{
by Marc-André Côté ${ }^{1}$
}

Supporters of forest and wood product certification are generally seeking to improve forest management and to ensure market access to forest products. Although wood products certification can be seen as an interesting marketing tool, it is doubtful whether it will improve forest management at the international level. Forest and wood product certification is already seen as a complementary tool to other existing instruments such as regulations and subsidies. However, a closer analysis shows that certification could be focused on the wrong countries, management units, scales of management, actors and problems to be potentially effective. This article aims to assess the possible impact of certification processes on the worldwide forest environment. The identification of possible limitations of forest product certification process could help to make that instrument more effective.

Key words: forest certification, environmental impact
Les supporteurs de la certification forestière et des produits forestiers cherchent généralement à améliorer l'aménagement forestier et à assurer l'accessibilité des marchés pour les produits forestiers. Même si la certification des produits forestiers peut être perçu comme un outil intéressant de marketing, on peut se demander si elle permettra d'améliorer l'aménagement forestier au niveau international. La certification forestière et des produits forestiers est déjà perçue comme un outil complémentaire à d'autres outils utilisés actuellement comme la réglementation et les subsides. Cependant, une analyse plus détaillée indique qu'il est possible que la certification soit centrée sur les mauvais pays, unités d'aménagement, niveau d'aménagement, acteurs et problèmes. Cet article vise à évaluer l'impact potentiel des processus de certification sur l'environnement forestier mondial. L'identification des limites possibles du processus de certification des produits forestiers pourrait rendre cet instrument encore plus efficace.

Mots-clés: certification forestière, impact environnemental

\section{Should We Focus on Soundly or Badly Managed $^{2}$ Areas?}

The concept of forest and wood product certification originated in order to slow down the rate of deforestation in tropical countries. Now the biggest efforts to certify forests are being made in northern developed countries where environmental regulations are already among the strongest in the world. Forest management practices in these countries tend to be closer to sustainability goals. This is probably the most ironic thing about forest and wood product certification.

Wood product certification processes, as they are presently designed, favour developed countries rather than developing ones for several reasons:

1) Countries are not at the same stage of development in their forest management evolution;

2) Countries do not have the same democratical structure;

3) Forests do not play the same role in every country;

4) Incentives may not be enough to favour core changes in forest management;

5) Incentives may be there for only a short period of time.

\section{Evolution of Forest Management Regimes}

Problems linked to forest management differ to a large extent from one country to another. International agreements on forestry practices should therefore consider that developing countries have more work to do than developed countries to reach sustainable forest management goals (Ross 1997).

${ }^{1} \mathrm{PhD}$ Candidate at the Faculté de Foresterie et de Géomatique, Université Laval, Québec City (Québec) G1K 7P4. E-mail: mac@moncourrier.com

${ }^{2}$ Sound forest management is defined in this article as forest management that maintains or increases the capacity of an area to produce forest goods and services.
Kimmins (1991) has distinguished four similar main stages in the historical evolution of forestry in a country:

1) Unregulated exploitation, leading to resource depletion;

2) Centralized administrative stage, leading to the failure to achieve sustained yield;

3) Ecologically-based forestry, leading to sustained yield and environment quality;

4) Social stage of forestry in which ecologically-based forestry must also satisfy diverse social needs.

Developed countries are mostly in the third stage and are preparing themselves to enter in the fourth one. Developing countries are, however, at an earlier stage in their forest management development.

This evolution has an impact on the maturity of forestry institutions within a country. The quality of communication between stakeholders, the degree of decentralization and the capacity of the public sector will depend on that level of maturity (Hearne and Bass 1997). These elements are essential components for sustainable forest management.

Wood product certification could have the potential to accelerate this development process. Nevertheless, it will be difficult to skip over steps since sustainable forest management cannot be reached overnight. A country cannot pass directly from a state of poor management to a state of sustainable forest management. It means that forest and wood product certification will probably reward a few corporations in developed countries that will be the first to manage forests on a sustainable basis.

\section{The Political Situation of a Country}

The Occidental democratic culture has influenced the development of sustainable forest management (SFM) standards. This probably explains the importance of public 
participation processes in SFM standards. However, requirements for public involvement in forest management may not conform to the culture of some countries. For example, although public participation and management based on consensus is usual in Scandinavia, it could be much more difficult in Russia. The national culture, the evolution of the forestry regime and the functioning of political institutions have a great impact on future public participation processes around the world. Forest management cannot be more democratic than other institutions within a country.

\section{The Functions of the Forest in a Specific Country}

The roles of forests differ from one country to another. In forested developed countries, forests have many functions. Forests are an important element of the economy of these countries. A well educated and wealthy population also uses the forest for other purposes, such as hiking, camping, fishing, and hunting. This population is aware of the global benefit of forests. The challenge is to manage the forest in order to satisfy everyone's needs.

In developing countries with extensive forests, such as Indonesia and Brazil, forests are an important contributor to local and national development. In most cases, these countries export forest products around the world.

In developed countries with small forested areas, like the majority of European countries, the forest industry is smaller and forests are more important for environmental protection and amenities than for timber activities. The challenge is rather to keep the forest-covered area intact. Populations of these countries perceive logging as a threat to their environment.

Finally, for developing countries with a limited forest area (the majority of countries in the world), forests are used to satisfy domestic needs, such as the consumption of fuelwood. Forests in these countries can also play an important role in environmental protection. Moreover, forests have to actively compete with alternate uses such as agriculture (Drake 1997). In these countries, the forest industry and possible exports are negligible functions.

A market-based instrument is probably not the best tool for improving forest management in the latter two groups of countries since they export a small proportion of their national production of forest products. Nevertheless, these countries are also facing important environmental problems regarding their forests.

In addition, this situation could create conflicts between consumers in developed countries and corporations in producer countries. Social values may differ, and even be conflicting, from a producing country to a consuming country. Sustainable forest management is therefore viewed differently from one country to another. This situation is part of the definition of sustainable forest management. However, consumers in developed countries may start to question the certificate given to a producer if sustainable forest management in a foreign country does not meet with their own perceptions of sound forestry. Consumers and some groups may have perceptions and concerns that are not relevant to the situation in other countries. For example, much of the criticism of Canada's forest practices comes from Europeans who are influenced by environmental values prevailing in Europe. A good example is the size of a forest clearcut. Europeans may feel that Canadian forest clearcuts are an environmental disaster whereas Canadians may believe the opposite. Moreover, Canadians have difficulty understanding the role of forests in the daily life of developing countries, such as Mexico.

Conflicts may also arise between producers from developed and developing countries. This situation will probably have an impact on the certification process. Some producers from developed countries may feel that their forest management is better than some others having the same certificate. The way in which sustainable forest management is conducted in a country will without doubt be questioned by another country, especially if certification is a marketing tool used by producers wishing to differentiate themselves on the market.

\section{The Size of Incentives}

Price premium is one of the arguments given by certification supporters to encourages producers to go ahead with a certification process.

Rice et al. (1997) have questioned possible premiums on prices that a producer may obtain for certified products. Will it be sufficient to incite producers to change their management and practices? These authors estimate that current patterns of unsustainable logging can be as much as five times as profitable as a more sustainable alternative in the Bolivian Amazonian forests. In fact, it is not surprising that less than oneeighth of $1 \%$ of the world's tropical production forests were operating on a sustained yield basis at the end of the eighties (Rice et al.1997).

There are some small market segments where price premiums may be expected for certified wood products. High added-value products such as doors or furniture could be markets where premium might be granted. Commodities markets will probably be less affected by wood product certification. Do people really want to pay more for their newspapers? It is doubtful that a young couple would be ready to pay, for example, $20 \%$ more for a certified house.

In addition, the number of groups in the processing and distribution chain will be a constraint to possible premiums. The ownership of products in the forestry sector changes several times before reaching the final consumer. Forest managers, sawmill owners, pulpmill owners, wholesalers, retailers, and consumers are all members of the chain of processing and distribution. It is difficult to transfer a possible price increase for an end product in the market to the stumpage value. All members of the chain of processing and distribution must obtain benefits from certified products in order to make certification effective on a large scale basis (IPF 1996).

Also, many products can be substituted for wood products. Higher prices will increase substitution with concrete, steel, plastic, or wood products from another producer.

The real benefit will be measured in terms of market shares for a company selling certified products (IPF 1996). Market share gains are also difficult to assess. It will depend on the nature of the products and the country where they are sold. Forest managers will carry out cost/benefit analyses before implementing sustainable forest management systems in order to certify forest and wood products. Forest managers who already managed their forest by respecting sustainable principles will see smaller costs linked to forest and wood product certification than forest managers who are at an earlier stage in their forest management development. Therefore, developed countries such as North American and European countries will 
probably be larger supporters of forest and wood product certification than developing countries. In fact, certification could have a negative impact in some developing countries. Some producers, believing that they cannot meet sustainable forest management standards or new regulations, may cut the forest more rapidly before moving to another part of the world where environmental regulations are weaker. These producers could even change their activities and move out of the forestry sector after having made money with a quick clearcut of the forest.

Sustainable forest management and certification have many benefits besides a premium on certified products and a gain of market shares. However, these last two benefits will be the main elements influencing a company's behaviour. Many other benefits, such as improvement of the corporate image and the enhancement of the employees' spirit, will probably not justify all the necessary investments in order to satisfy the requirements of the SFM standard.

\section{A Volatile Incentive}

A premium on price will probably be given first to certified wood products distributed on the market. There should not be a price distinction between certified and non-certified wood products after a short period of time. Experience on ecolabelling for other products suggests that a price premium tends to be a short-term phenomenon (IPF 1996). Then again, this situation favours corporations from developed countries that will more quickly meet sustainable forest management requirements.

Corporations from developing countries will receive less benefit after having done all the necessary changes to conform with sustainable forest management and certification standards. Certification has thus more potential for encouraging small changes in forest management rather than bigger ones.

\section{What is the Optimal Level for Assessing Sustainability of Forest Management?}

Sustainable forest management can be assessed at several levels. In the case of wood product certification, sustainability is assessed at a forest management unit level. Governments of many countries are also in the process of measuring sustainable forest management at a national level by using criteria and indicators. Are these two different measures compatible and comparable? Which level is better?

An answer can be obtained by determining who is responsible for factors affecting sustainability of the forest environment. For example, regulations have a great impact on possible sustainability of forest management. Regulations are defined at the national or the sub-national level by government agencies. Environmental impacts of timber harvesting operations also have a great impact on the sustainability of forest management. Environmental impacts depend on the forest manager at a management unit level and on the code of sound forest management that is usually developed by forest agencies.

In fact, governments are responsible for several elements in SFM standards. The development of regulations, policies and code of practice, the allocation of land and resources, the respect of First Nations' rights, and the respect of workers' rights are a few examples. Corporations control the quality of their forest operations. The planning and the execution of silvicultural treatments is the aspect of existing SFM standards that concerns corporations.

Moreover, the government is supposed to monitor the work done by corporations according to the requirements of the regulations. A third-party certification mechanism that evaluates the government's job of monitoring could give interesting results. In other words, evaluating the work done by the government authorities to improve forest management in the country could increase the positive impact of forest certification.

Finally, establishing sustainable forest management systems serves several aims. Society in general will get more benefits from sustainable forest management practices than companies will as forest managers. Maintenance of the quality of the hydrological cycle, conservation of soils, protection of landscape amenities, and maintenance of national biodiversity are not real benefits for a forest product company. Assessment should be done for sub-national units if benefits are generally obtained at these levels.

\section{Should We Assess Land Management or Forest Management?}

Actors involved in deforestation are a larger group than actors involved in forest management. In a sense, conflicts between land users are at the heart of deforestation, meaning that deforestation is not necessarily a forestry issue.

In many parts of the world (in developing and developed countries), agriculture, urbanization and industrialization eat up part of forested areas every day. Forest management can be totally sustainable, but if there is no overall land planning for the country, forest areas will decrease. National land management may have a greater impact on forests than forest management by itself.

For example, a river crossing a country may receive waste water from a mill before going into a forested area. It is therefore difficult to assess the impact of timber harvesting on the water quality. The price of a crop can rise so much during a season that farmers may find it more profitable to cut forested parts of their properties in order to enlarge their field. This obviously represents bad forest management, but farmers who have cut their forests are not particularly interested in wood product certification. Agriculture has a bigger impact in developing countries. Current assessments show that agriculture is now responsible for two-thirds of tropical deforestation (Bass 1997).

Other users of the territory have an impact on the forest environment that a forest manager cannot control. Sustainable forest management is therefore a national issue that must be addressed by all users of the territory and not only by forest stakeholders.

Existing certification processes minimize the role of the following factors on forest degradation:

- poverty;

- population growth;

- urbanization;

- high unemployment rates in developing countries;

- indebtedness;

- industrial trading structure;

- misguided multilateral aid policies;

- environmentally insensitive private foreign investments;

- inflexible forestry institutions;

- over-concentrated industrial control over forests; 
- inequitable access to forests;

- poorly informed public and consumers;

- level of corruption in the country;

- position and status of women in the society;

- level of consumption of wood products in developed countries;

- inequalities in land distribution;

- drug cultivation;

- natural catastrophe.

(Shumba and Baker 1998, Bass 1997, Eastin 1996, Humphreys 1996, Dudley et al. 1995).

Nevertheless, industrial development often initiates other causes of forest degradation. For example, logging roads open the forests up for further exploitation by squatters, miners, and settlers. In addition, the pulp manufacturing in developing countries also has a significant effect on the rate of deforestation. The timber industry is now able to utilize areas of natural forest that used to be uneconomical to harvest. Moreover, the forest products industry may play an important role by corrupting weak governments (Dudley et al. 1995, Barbier et al. 1992).

However, no real consensus has been reached on the different roles of various factors that could affect deforestation rates. Too often, causes of deforestation have been analyzed in the forest context alone. This is an error because causes of deforestation are numerous and linked together. The agriculture, livestock, energy, and socioeconomic sectors all compete for forest land use or for forest resources (Saxena et al. 1997).

Sustainable forest management will only be possible if the roots of forest problems are addressed. These problems will have to be resolved at both technical and political levels. These issues are not addressed by forest and wood products certification as it is now designed (Jordan 1996, Bass 1997). In fact, policies from outside the forest sector often have a greater impact than forest policy on people and their utilization of the forest (Mayers 1998). The tendency to define forestry narrowly has blurred the sector's linkage with other sectors of the national economy (Shumba and Baker 1998).

\section{Are We Simply Moving Environmental Problems to Another Part of the World?}

Sustainable forest management could mean fewer and smaller forest cuts in order to satisfy other users of the territory. For example, the creation of a conservation park or bigger wildlife corridors might affect the timber activity in a forested area. This situation could decrease the overall annual allowable cut in a country if no other silvicultural investments are made to increase the productivity of the forest in other part of the territory. However, the world's demand for wood products is growing. This means that the demand for industrial timber will have to be satisfied by another region of the world if no product substitution occurs.

The best example of that situation is given by the enforcement of new environmental regulations on the western coast of North America that should lead to a reduction of the annual allowable cut in the short term. To satisfy the American demand for timber, production will have to increase in other regions such as eastern Canada, Sweden, Finland, Chile, and New Zealand. Without a rise in consumption of substitute products, a reduction in consumption of wood product, and an increase of silvicultural investments, some industrial timber produc- tion could be transferred to another part of the world. Sustainable forest management in one part of the world could mean higher environmental degradation in other parts if the production is transferred to countries having weaker regulations.

Moreover, a regional shortage in timber supply could result in a temporary price increase. A higher price for timber may incite some producing countries to increase harvesting. However, a higher price for industrial timber could also justify further silvicultural investments.

\section{Does Sustainable Forest Management Mean a Better Forest Environment?}

The present economic system encourages consumption. This consumption of goods and services requires a large amount of all kinds of wood products. As long as the consumption issue is not addressed adequately there will be an extreme pressure on natural resources. The problem is not production but consumption.

The level of consumption of industrial forest products in developed countries is far higher than in developing countries. Many environmental problems around the world could be addressed if a change in the level of consumption would occur. This means changes in the way of living in developed countries. Moreover, changes in the way of living and consuming would no doubt avoid many future environmental problems. The consuming habits of people from developed countries are a threat to the world's forests since those habits may be exported to developing countries. At the moment, there is no trend towards a decrease in consumption in developed countries.

The concept of sustainable development gives the wrong impression that continual growth in consumption is possible without damaging the environment. It is difficult to have an increase in economic activity in answer to demand for products without having an increase in the consumption of natural resources. Continuous growth refers in this case to continuous growth in the production of wood products. It means an increase in the extraction from forest ecosystems. Although they are renewable, natural resources are still limited (Bartlett 1998). A better use of natural resources may allow a possible increase in the level of consumption, but that increase will always be limited.

Foresters will continue to develop systems to protect and increase the growth of forests around the world. This is their main task. Nevertheless, anomalies in our economic system must be addressed by the whole society.

Experience shows that humans start to be concerned about a resource only when it becomes scarce. In fact, the forestry sector will probably be put under strong pressure only when forest resources are depleted to the point that continuing use of its products will be uneconomical. The fisheries sector serves as an example of that situation. It seems that forests are not yet a rare enough resource to be a universal concern.

\section{Conclusion}

The impact of certification might be localized in only a few countries. Thus, certification will probably have little impact on the worldwide forest environment. Developed countries should benefit from certification initiatives. On the other hand, forest product certification is not likely to improve forest management in developing countries even though they are facing critical environmental problems. 


\section{References}

Barbier, E.B., J.C. Burgess, B.A. Aylward and J.T. Bishop. 1992. Timber Trade, Trade Policies and Environmental Degradation. Discussion Paper 92-01. London Environmental Economics Centre. 51 p.

Bartlett, A.A. 1998. Reflections on Sustainability, Population Growth and the Environment - Revisited. Renewable Resources Journal: 6-22

Bass, S. 1997. Certification as a Manifestation of Changing Roles in Forestry. Conference Proceedings of the Oxford Summer Course Programme 1996. pp. 105-112. OFI publication.

Drake, D. 1997. A Common Understanding And A Binding International Commitment - The Keys To Progress Toward Sustainable Forest Management Worldwide. (Editorial). For. Chron. 73(5): 522. Dudley, N., J.P. Jeanrenaud and F. Sullivan. 1995. Bad Harvest? The Timber Trade and the Degradation of the World's Forests. Earthscan Publications Ltd. 204 p.

Eastin, I.L. 1996. Marketing Strategies to Promote Sustainable Forest Management in Tropical Africa. FPRDI Journal 22(1): 79-88. Hearne, R.R. and S. Bass. 1997. Private Sector Forestry: A Review of Instruments for Ensuring Sustainability. IIED Report, Forestry and Land Use Series no 11.62 p.
Humphreys, D. 1996. Forest Politics. Earthscan Publications Ltd. 299 p.

International Panel on Forests. 1996. Compte-Rendu de la 4ème Réunion. Available HTTP: www.un.org/dpcsd/dsd/ipf.htm

Jordan, G.H. 1996. Forest Certification and Timber Tracing: The Issue and the Needs. Journal of the Institute of Wood Science 14(1): 15-20.

Kimmins, J.P. 1991. Balancing Act. UBC Press. 244 p.

Mayers, J. 1998. How Forest Policies Have Evolved. Lecture at the Oxford Forestry Institute. Unpublished. 19 p.

Rice, R.E., R.E. Gullison and J.W. Reid. 1997. Can Sustainable Management Save Tropical Forests? Scientific American (April): 34-39.

Ross, B. 1997. Following the Sustainability Fashion. The Pulp \& Paper International (July): 5.

Saxena, A.K., J.C. Nautiyal and D.K. Foot. 1997. Analysing Deforestation and Exploring Policies for its Amelioration: a Case Study of India. Journal of Forest Economics 3(3): 253-280.

Shumba, E.M. and S. Baker. 1998. Forestry Challenges in the 21st Century: The 15th Commonwealth Forestry Conference Perspective. Commonwealth Forestry Review 77(1): 1-3. 